\title{
Model test of long-term drainage consolidation of floating mud
}

\author{
Jianbao $\mathrm{Fu}^{1,2,3,4,5 a}$,Jinfang $\mathrm{Hou}^{1,2,3,4,5 b}$ \\ 1. Tianjin Key Laboratory of Soft Soil Characteristics and Engineering Environment, Tianjin \\ Chengjian University, Tianjin 300384, China \\ 2. Tianjin Port Engineering Institute Co., Ltd. of CCCC First Harbor Engineering Co., Ltd., Tianjin \\ 300222, China \\ 3. CCCC First Harbor Engineering Company Ltd., Tianjin 300461, China \\ 4. Key Laboratory of Port Geotechnical Engineering, Ministry of Communications, PRC, Tianjin \\ 300222, China \\ 5. Key Laboratory of Tianjin Port Geotechnical Engineering, Tianjin 300222, China \\ a276339170@qq.com, b25700496@qq.com
}

\begin{abstract}
Keywords: Model test. Long-term drainage consolidation. Floating mud.
Abstract. Model test of long-term drainage consolidation model of floating mud was carried out in this paper. The test was carried out in a large consolidation model test tank developed by the laboratory itself. The test reinforcement period is 691 days. After the reinforcement by a preloading load of $80 \mathrm{kpa}$, the final pore water pressure is close to zero which indicates that the floating mud basically complete the main consolidation. The latter stage settlement is mainly secondary consolidation settlement. Under the condition that the soil is basically completely consolidated, the ultimate shear strength of the cross plate is only $13.1 \mathrm{kPa}$, which is still not ideal. The settlement of the floating mud with little strength and high water content at the beginning is very large after drainage consolidation and the strength increase is also very large. However, the absolute value of the strength after reinforcement is relatively low. It should be paid attention to by the engineering community.
\end{abstract}

\section{Introduction}

Due to hydraulic separation during land reclamation, floating mud with a certain thickness is often formed locally. Due to the tight construction period, it is necessary to reinforce the foundation of the newly reclaimed floating mud. However, the value of the strength increase of floating mud foundation after 3 to 5 months of preloading with a high settlement is relatively small, which cannot meet the application requirements of the foundation and even requires secondary treatment. Therefore, engineers have doubts about the reinforcement effect of vacuum preloading method to reinforce floating mud, and even consider the drainage consolidation method is not suitable for floating mud reinforcement.

In view of this situation, experimental study on long-term drainage consolidation model of floating mud was carried out in this paper. The result can help to clarify the long-term drainage consolidation mechanism of the floating mud, and make clear whether floating mud can reach the ideal reinforcement effect after long-term drainage consolidation. It will provide technical support for floating mud treatment.

\section{Test method}

The test was carried out in a large consolidation model test tank developed by the laboratory itself. The test tank is a steel cylinder with an effective inner diameter of $960 \mathrm{~mm}$ and a depth of $1200 \mathrm{~mm}$. The loading plate with steel frame and counterweight block are used for loading, as shown in figure 1 and figure 2.

In the test, the thickness of the loaded floating mud is $0.9 \mathrm{~m}$. Lay a plastic film on the surface of the floating mud to prevent the sand cushion layer from directly contacting with the floating mud. Plastic drain boards were insert into the floating mud. Lay sand cushion on plastic film with a thickness of 
about $0.25 \mathrm{~m}$. The first level was added to $16.1 \mathrm{kPa}$. The second level was increased to $41.7 \mathrm{kPa} 100$ days later. The third level was added to $80 \mathrm{kPa} 140$ days later.

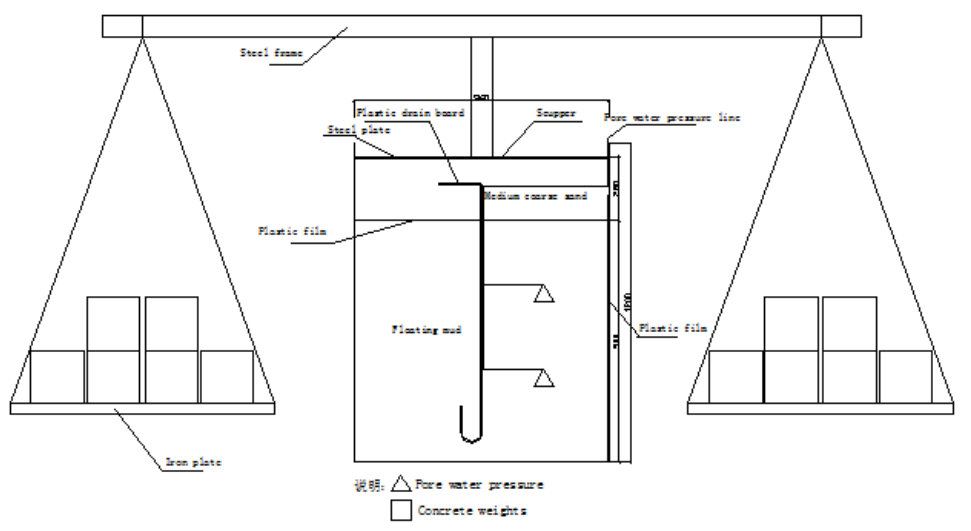

Fig. 1 Test diagram

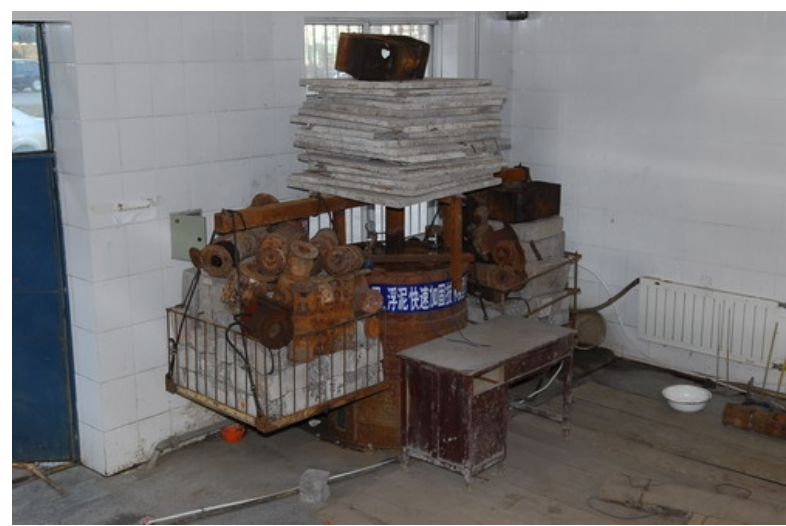

Fig. 2 Test scene map

\section{Test result}

The test reinforcement period is 691 days. The pore water pressure and settlement were monitored during the reinforcement, and the effect of the reinforcement was tested immediately after the reinforcement.

Pore water pressure monitoring results. The monitoring result of pore water pressure is shown in figure 3.

Pore water pressure tends to dissipate during consolidation, which indicates that the soil is continuously consolidated and the effective stress is continuously increasing. After each loading, the pore water pressure has obviously increased suddenly, and gradually dissipated with the passage of time. Finally, the pore water pressure is close to zero, which indicates that the soil body has basically completed the main consolidation. In the final stage of the test, the pore pressure increased slightly because the soil displacement was very small in the later stage. In order to prevent the influence of water evaporation on the test results, a small amount of clear water was injected into the test tank.

Settlement results. The settlement monitoring results are shown in figure 4. During the whole strengthening process, the total settlement of the test soil with lateral deformation constraints is 429 $\mathrm{mm}$, which is $47.7 \%$ of the height of the test soil, and the settlement is very considerable. After each loading, the settlement rate increased obviously, and then gradually decreased with the passage of time. During the last few months of consolidation, there has been no obvious increase in settlement, which indicates that the main consolidation of the soil is basically completed at this time, while the latter settlement is mainly secondary consolidation settlement. 


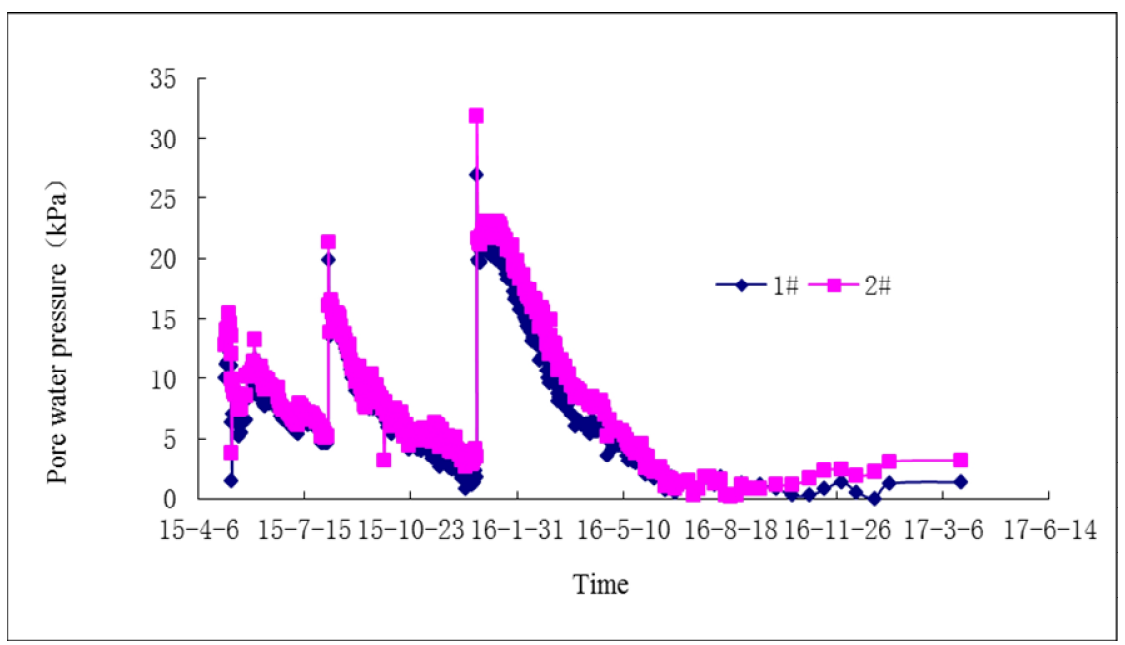

Fig. 3 Cure of pore water pressure $\sim$ time

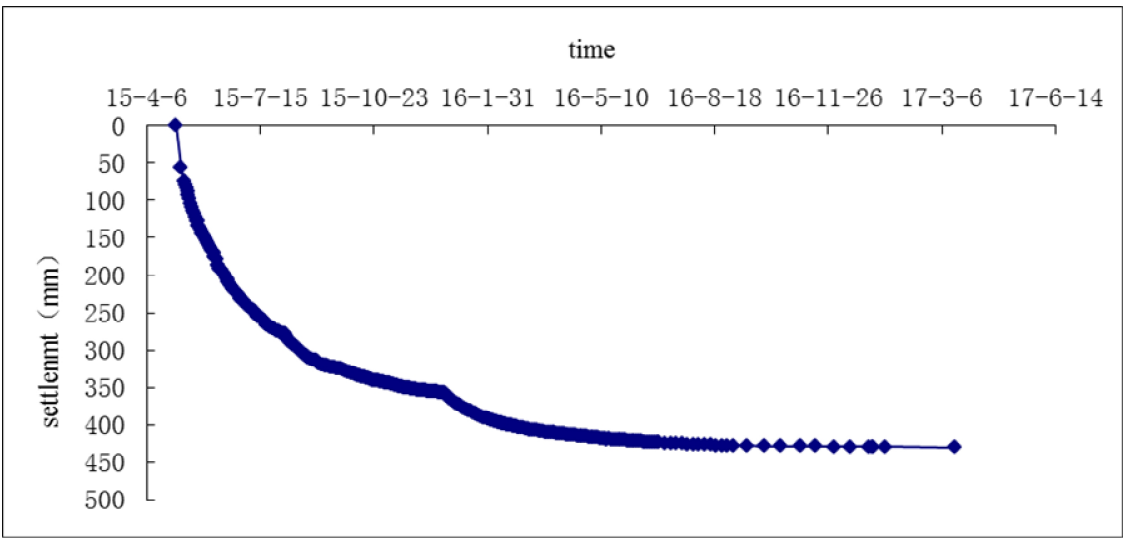

Fig. 4 Cure of settlement $\sim$ time

Cross plate strength test results. After reinforcement, cross plate strength test was carried out. The specific location of the cross plate test is shown in figure 5. The test results are shown in table 1 .

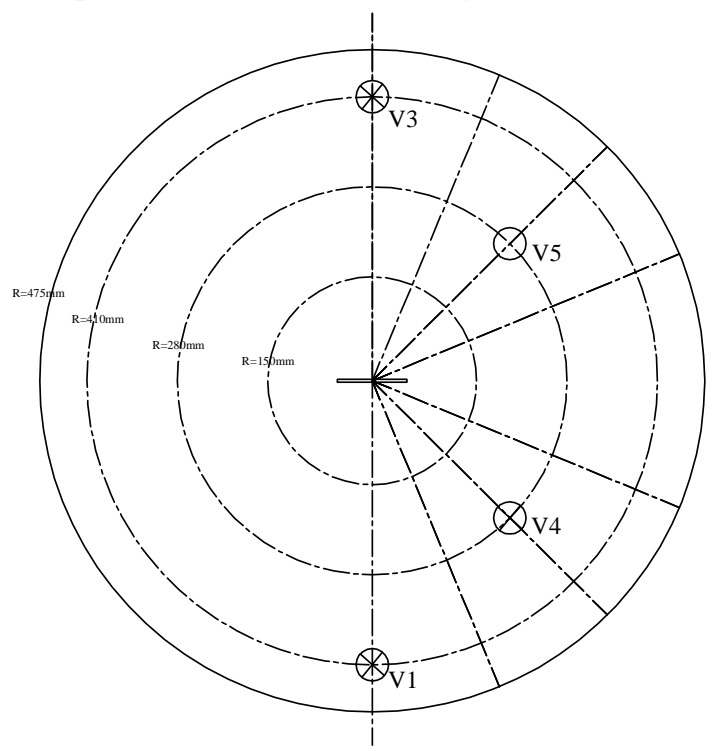

Fig. 5 The position of cross plate after test

Table 1 Cross plate strength test results

\begin{tabular}{cccccc}
\hline Measuring point number & 1 & 3 & 4 & 5 & Average value \\
\hline Strength $(\mathrm{kPa})$ & 11.3 & 11.8 & 13.6 & 15.6 & 13.1 \\
\hline
\end{tabular}


From table1, it can be seen that after 691 days consolidation, the main consolidation settlement has been basically completed, and the object to be consolidated has changed from mud with no strength to soil with certain strength, and the reinforcement effect is very obvious. However, the average cross plate shear strength of the reinforced soil is only $13.1 \mathrm{kpa}$, and the ultimate strength is relatively low, which is determined by the nature of the soil itself. Due to its high clay content and large plasticity index, the internal friction angle of this kind of soil is small, which affects the strength increase after reinforcement.

Result of soil sampling test. In order to minimize the disturbance to the soil sample during the sampling process, a ring cutter was used to sample the soil sample. At the same time, in order to study the reinforcement effect of different positions in the solid, samples were taken at different positions away from the drain board.

After reinforcement, the moisture content of soil is $54 \% \sim 69 \%$, which is obviously lower than $140 \% \sim 160 \%$ before reinforcement. The reinforcement effect is different at different distances from the drain board, which shows that the soil moisture content is different at different distances, as shown in figure 6.

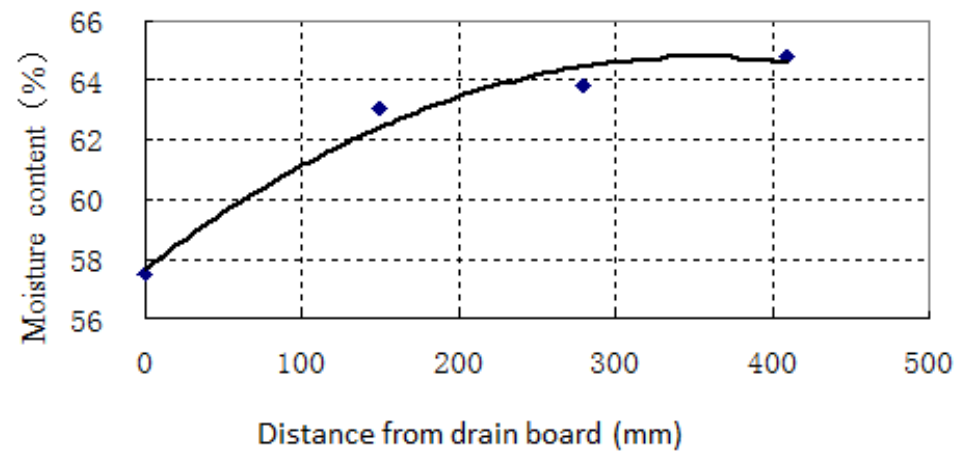

Fig. 6 Moisture content of reinforced soil

As can be seen from figure6, the soil near the drain board will consolidate faster after reinforcement. Therefore, the water content is lower, while the soil at a certain distance from the drain board will slightly increase its water content as the distance from the drain board increases, but the overall change range is very small.

In order to further study the consolidation characteristics of the soil, 10 groups of consolidation tests were carried out after consolidation. The maximum consolidation pressure was as high as 1600 $\mathrm{kpa}$, as shown in figure7.

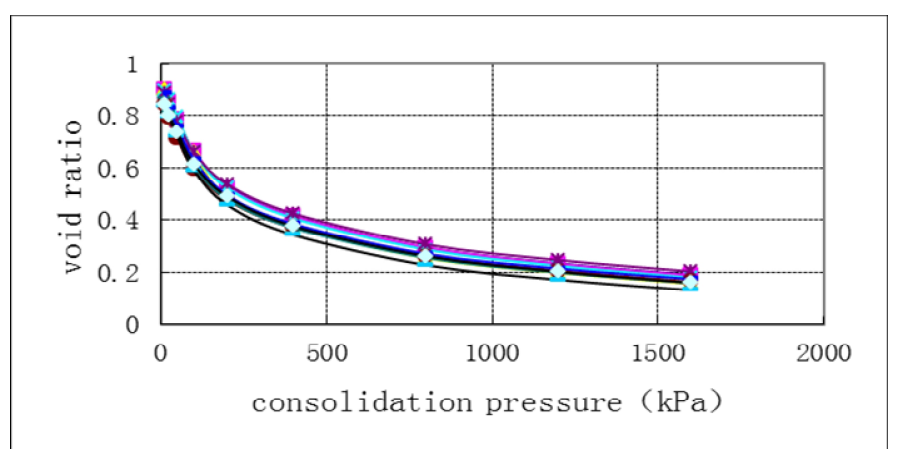

Fig. 7 Moisture content of reinforced soil

The consolidation coefficient of soil can be calculated from the consolidation curve. According to the test results, the consolidation coefficient of the soil after the test is $1.1 \times 10^{-4} \mathrm{~cm}^{2} / \mathrm{s}$. According to this consolidation coefficient, this test requires 600 days of consolidation time to reach $95 \%$ consolidation degree.

According to the indoor consolidation test results after reinforcement, the settlement calculated by the foundation calculation system under the external load of $80 \mathrm{kPa}$ is $44 \mathrm{~mm}$ (including unloading 
rebound settlement and secondary consolidation settlement). That is to say, the settlement of $900 \mathrm{~mm}$ thick mud during the test is $429 \mathrm{~mm}$. If the preloading is continued until it is fully consolidated, the settlement will increase $44 \mathrm{~mm}$. It shows that the consolidation degree of foundation settlement during the test reached more than $91 \%$.

\section{Conclusion}

Through the model test of floating mud under a preloading load of $80 \mathrm{kpa}$, the following conclusions are obtained:

(1) The pore water pressure gradually dissipates, and the final pore water pressure is close to zero. It indicates that the floating mud used in the test basically complete the main consolidation.

(2) The pore water pressure does not obviously dissipate in the later stage of consolidation, but the settlement is still slowly developing. It indicates that the latter stage settlement is mainly secondary consolidation settlement.

(3) Under the condition that the soil is basically completely consolidated, the ultimate shear strength of the cross plate is only $13.1 \mathrm{kPa}$, which is still not ideal.

(4) The settlement of the floating mud with little strength and high water content at the beginning is very large after drainage consolidation and the strength increase is also very large. However, the absolute value of the strength after reinforcement is relatively low. It should be paid attention to by the engineering community.

\section{Acknowledgements}

This work was financially supported by the Tianjin Key Laboratory of Soft Soil Characteristics and Engineering Environment (2013SCEEKL03).

\section{References}

[1] Jiang Yongchun. Study on Unloading Criterion of Surface-layer Improvement Technique of Slurry Stratum [D]. Guangzhou: Guangzhou University, 2013. (in China)

[2] LIU Ji-fu, JIANG Yong-chun. Requirement of shallow improvement of foundation with dredged slurry by vacuum preloading [J]. Port \& Waterway Engineering,2015, (5): 191-196.(in China)

[3] ZHANG Wen-bin. Experimental study on strength increasing rule of hydraulic fill mud consolidated by vacuum preloading [J]. Port \& Waterway Engineering,2016, (8): 151-157.(in China)

[4] FENG Jun,LIU Ai-min,GAO Zhi-yi. Effect Analysis on Strengthening Mud Flow by Vacuum Preloading [J]. China Harbour Engineering, 2011,( 2) : 35 -38. (in China) 